\title{
Ethical Issues in the Emergency Department: Consent for Procedure Training on Newly Deceased Patients
}

\author{
Marta Karczewska*
}

\section{SCENARIO}

You are the medical student on call in a busy emergency department while a 62 year old male in cardiac arrest is brought to the resuscitation room by the paramedics. The paramedics report that they have been engaging in unsuccessful CPR manoeuvres and that the patient did not have a shockable cardiac rhythm on the way to the hospital.

Despite the dismal prognosis, resuscitation efforts (CPR, intubation, epinephrine and atropine) continue until the patient's death is declared, twenty minutes later. At this point, the staff physician removes the endotracheal tube placed in the patient's throat, turns to you and asks you if you wish to practice intubation on the body. He explains that this is a widespread practice and that it is essential to your medical training. The patient's family is waiting outside the room, still unaware of the situation.

You are faced with an ethical dilemma: is it right to proceed with such a procedure without the patient's family's approval? You wonder if it is justified to practice medical procedures and skills on cadavers in such a setting. In other words, in a newly deceased patient, is the practise of intubation without familial consent an ethically acceptable action?

\section{BACKGROUND INFORMATION}

Anatomy lessons on cadavers have been part of medical training for years, along with the practice of medical procedures on newly deceased patients in a clinical context. The former is accepted as being ethically correct, given that donors or their family have given consent for the use of their body as a medical

\footnotetext{
*To whom correspondence should be addressed: Marta Karczewska

3787, Côte-des-Neiges, Apt 329

Montreal, Quebec

H3H 1 V9

marta.karczewska@mail.mcgill.ca
}

learning tool. However, the latter is subject to more fervent debate. The purpose of this practice is to develop skills in delicate lifesaving procedures. It is crucial to acknowledge that in many cases, this type of training may be the only opportunity a future health professional has before attempting to perform the same procedure under stressful conditions in which someone's life may be in danger.

The main arguments in support of the practice of procedures like endotracheal intubation and central venous catheter placement on the newly deceased is the overall benefit to society (1). In fact, it gives the opportunity for physicians to develop skills they could not acquire otherwise. For instance, a physician may be practicing in a rural area where the frequency of a specific procedure is too low to keep his or her skills up to date, thus diminishing their competency to perform the procedure on subsequent patients. Furthermore, "resuscitation techniques differ from other procedures in medicine in that they are usually performed only in critical situations, and thus the opportunities to learn and practice them are inherently limited" (2). Newly deceased bodies offer the opportunity to practice with no danger to someone's health. This type of approach offers an anatomically ideal model at a low monetary cost. Therefore, allowing students to practice on recently deceased body benefits society in that it can keep physicians competent in certain areas of their practice while preventing harm to living patients.

As described in the clinical scenario, the most commonly practiced procedure on freshly expired bodies is endotracheal intubation (3). Central venous catheter insertion, cricothyrotomy, pericadiocenthesis, thoracotomy, venous cutdown, intra-osseous needle placement and even liver biopsy are also practiced, as was reported in an anonymous national survey conducted in the United States by Burns et al. (2). More than one third of the medical schools in this study admitted performing procedures on newly deceased 
patients, although the frequency of consent was only $10 \%$. Fourre's (3) results confirmed this observation, with "forty-seven percent of the respondents [who have] indicated [that] procedures were performed on the recently deceased for teaching purposes in their Emergency Departments" and "seventy-six percent [of the Program Directors who] stated they "almost never" obtain consent from family members" (3). Table 1 reviews the results of the above studies.

\begin{tabular}{|l|l|}
\hline $\begin{array}{l}\text { Table 1: INCIDENCE OF PRACTICE ON } \\
\text { NEWLY DECEASED PATIENTS IN THE }\end{array}$ \\
\begin{tabular}{l} 
USA (2,3) \\
\hline $\begin{array}{l}\text { Proportion of Hospitals performing } \\
\text { procedures on newly deceased patients }\end{array}$
\end{tabular} $\begin{array}{c}39 \%(2) \text { and } \\
47 \%(3)\end{array}$ \\
\hline $\begin{array}{l}\text { Proportion of Emergency Medicine } \\
\text { programs performing procedures on } \\
\text { newly deceased patients }\end{array}$ & $63 \%$ \\
\hline $\begin{array}{l}\text { Proportion of Neonatal Intensive Care } \\
\text { programs performing procedures on } \\
\text { newly deceased patients }\end{array}$ & $58 \%$ \\
\hline Frequency of request for consent & $10 \%$ \\
\hline
\end{tabular}

Although the benefits of practicing procedures on patients who have just passed away can be tremendous, the issue of obtaining consent to do so has been widely debated in the medical literature. The following ethical analysis focuses on both older and newer articles published on the topic of consent for practice of medical procedures on recently-dead patients.

\section{ETHICAL QUESTION: IS CONSENT REQUIRED?}

\section{Arguments Against Seeking Consent}

Some researchers claim that it is not necessary to obtain consent for the practice of medical procedures on deceased bodies (1). They argue for an "exception to the requirement for informed consent in this limited case because there is substantial social benefit to be gained, there is no risk to the dead person, and families could not realistically be expected to discuss consent at such a difficult time" (2).

In fact, one may think about the harm and emotional distress caused to families by raising questions of consent in such difficult settings. Indeed, it may be very challenging and delicate for the physician to ask for permission when faced with the death of his patient. Therefore, specific training may be needed for physicians who make postmortem requests of families (4). Additionally, "requiring physicians to attempt to obtain consent inhibits the practice because many physicians are reluctant to ask, for fear of burdening the family" (5). This perspective follows the general ethical principle of nonmaleficence, or not causing harm to the patients and their family.

Asking for consent is sometimes not possible despite all best efforts, simply for technical reasons. For example, families are not always disposed for discussion or cannot be reached. It would be deplorable to loose an opportunity to train physicians in life-saving medical skills in this situation.

Finally, there is the general idea that "the limited rights of the dead must be balanced against the rights of the living" (5). The idea is that living patients have the right of expecting quality treatment from skilled physicians and this can be achieved at the cost of practicing on the newly deceased. In other words, "possible burdens to the deceased family are accepted for societal good" (5).

\section{Arguments for Seeking Consent}

In response to the last argument that the benefits of the living must be balanced against the rights of the dead, it is interesting to make a parallel with cadaveric organ donation. Despite the tremendous advantages of a new organ to a living patient, "formal consent from a surrogate is required for medical procedures such as organ donation and autopsy, and for disposition of the body. These precedents suggest the need for consent for non-indicated training procedures" (4). In essence, consent should be mandatory for the practice of procedures on recently deceased patient, just as it is for organ donation.

Second, it may appear as though obtaining consent for practicing procedures on the newly-deceased would be limited. However, a study performed in Norway reveals that about $69 \%$ of people would allow their own body to be used for teaching intubation techniques, whereas $58 \%$ would agree that the body of a close relative could be used for teaching purposes (6). Another study performed at two urban academic military Level-1 trauma centers found that $75 \%$ of families would allow medical procedures to be practiced on their newlydeceased relative and that $60 \%$ of families would be "upset" with medical staff for doing so without their consent (7). Nevertheless, it is clearly a challenging experience for a physician to seek consent from families who experience the unexpected death of a loved one. This attitude is likely part of the reason why consent is not obtained by physicians in the majority of cases. Yet the consensus in the literature is that most families would be willing to let trainees practice life-saving procedures on their newly deceased loved ones, granted that they are asked for consent first (5).

Third, the concept of truth-telling is an important 
reason for seeking consent. Disclosure, honesty and integrity are all part of a physician's code of ethics. Although the patient is no longer alive, a doctor remains accountable to their patient's family and relatives. Furthermore, the harm caused to a family by practicing procedures on their loved one can greatly vary depending on religious or spiritual beliefs, thus heightening the need for familial consent.

Fourth, general distrust toward the medical community is a possible consequence of not obtaining consent for medical training on the newly deceased patient. The Society for Academic Emergency Medicine (SAEM) reviewed the question of consent for practicing medical procedures on recently deceased patients in 2004 and concluded that consent should be sought: "Given the importance of protecting trust in the profession of medicine and the existing evidence that the public would expect that consent be obtained, SAEM recommends that families be asked for consent before practicing procedures on the newly dead" (5).

Lastly, the SAEM touches on the idea that "failure to ask prevents the survivors from saying no, preventing the practice needed by trainees, but also fails to allow the survivors an opportunity for altruism in saying yes" (5).

\section{RECOMMENDATIONS AND GUIDELINES ON THE PRATICE OF PROCEDURES}

As stated earlier, the SAEM advises that consent is taken from family before attempting manoeuvres on freshly deceased bodies. The American Medical Association (AMA) Ethical Guideline concurs with the above suggestion, adding the recommendation that the practice of procedures should not be undertaken in situations where it is impossible to obtain consent. Likewise, the American Heart Association's Emergency Cardiac Care (ECC) committee suggests that institutions should develop guidelines with clear and specific procedures to follow before the use of the newly dead for teaching purposes. Table 2 summarizes those recommendations.

\section{ALTERNATIVES}

Mannequins designed for the practice of medical procedures are being increasingly used as an alternative method of learning. A study comparing the success rates of intubation between paramedics who practiced on mannequins and others who practiced on cadavers showed comparable outcomes (10). Artificial models provide a safe way to learn the manoeuvres and skills involved in acts like tracheal intubation. However, the mechanical and emotional aspects of training on a mannequin are very different from those on a live human being. It would therefore be naive to view them as an entirely equivalent learning method. In fact, two other studies have found that the practice of intubation on cadavers is superior from that of mannequins (11, 12). Nonetheless, mannequins can be regarded as an adequate first step toward the learning of a new skill. Hauswald believes that "psychomotor skills are best learned on models" (13). After solid skills are acquired with the mannequin, further teaching should be undertaken on consenting live patients. This ought to be done under the guidance of an expert in controlled circumstances like those of anesthesia induction in the operating room. "In this environment, adequate numbers of subjects can be managed, mistakes are quickly caught, and repercussions to the patient and student are minimized" (13). Also, "the teaching of lifesaving skills should be the culmination of a structured training sequence, rather than relying on random opportunities" (8). Medical schools could therefore promote a rotation through the anesthesia department to guarantee that all their trainees are consistently

\begin{tabular}{|l|l|}
\hline Table 2: RECOMMNDATIONS AND GUIDELINES \\
\hline $\begin{array}{l}\text { Society for Academic } \\
\text { Emergency Medicine } \\
\text { (SAEM) }\end{array}$ & $\begin{array}{l}\text { "Although limited, the existing studies suggest that a portion of families would consent to } \\
\text { procedures on their recently deceased loved ones and that a majority of the public believes that } \\
\text { consent should be obtained. Therefore, the SAEM recommends that families be asked for consent } \\
\text { before practicing procedures on the newly dead" (5). }\end{array}$ \\
\hline $\begin{array}{l}\text { American Medical } \\
\text { Association } \\
\text { (AMA) }\end{array}$ & $\begin{array}{l}\text { Ethical Guideline: "Physicians should inquire whether the deceased individual had expressed } \\
\text { preferences regarding handling of the body or procedures performed after death. In the absence of } \\
\text { previously expressed preferences, physicians should obtain permission from the family before } \\
\text { performing such procedures. When reasonable efforts to discover previously expressed preferences } \\
\text { of the deceased or to find someone with authority to grant permission for the procedure have failed, } \\
\text { physicians must not perform procedures for training purposes on the newly deceased patient" (8). }\end{array}$ \\
\hline $\begin{array}{l}\text { American Heart } \\
\text { Association's } \\
\text { Emergency Cardiac } \\
\text { Care (ECC) committee }\end{array}$ & $\begin{array}{l}\text { Guidelines for 2000: "All institutions providing ECC should develop guidelines for and mechanisms } \\
\text { to address these sensitive issues [of research and procedures on the newly dead]... Informed } \\
\text { consent to use the newly dead for research or training should be obtained unless institutional } \\
\text { guidelines specifically address circumstances under which consent is unnecessary" (9). }\end{array}$ \\
\hline
\end{tabular}


competent in intubation. More recent research, however, could lead to the identification of the optimal learning method, given that simulation is evolving and that more realistic models are created for learners.

\section{CONCLUSION}

Performing medical procedures on a newly deceased patient is common practice according to surveys conducted in the U.S., although it is estimated that consent is seldom requested. A literature review on the ethical dilemma of requesting consent from families reveals arguments both in favour and against such practice. However, the consensus is that most families are willing to let trainees practice life-saving procedures on their newly deceased loved ones, provided that they are asked for consent. The recommendations are that practice of procedures on cadavers should be done only when agreed to by the next of kin. In the case that consent cannot be obtained, it is recommended that the trainee should abstain from performing the procedure. Therefore, the staff physician in the clinical scenario may be right that practicing on the newly deceased is a valuable asset to the student's education, but at the same time, the student and the physician must remain aware of their need to obtain consent. Alternatives for skill acquisition are the practice of intubation on a consenting patient in the operating room, as well as simulation on mannequins. On a broader scale, written policies should be available in teaching centers to guide the practice of procedures on the newly deceased patients.

\section{REFERENCES}

1. Orlowski JP, Kanoti GA, Mehlman MJ. The ethics of using newly dead patients for teaching and practicing intubation techniques. N Engl J Med. 1988; 319:439-441.
2. Burns JP, Reardon FE, Truog RD. Sounding board: Using newly deceased patients to teach resuscitation procedures. N Engl $\mathrm{J}$ Med. 1994; 331: 1652-5.

3. Fourre MW. The performance of procedures on the recently deceased. Acad Emerg Med. 2002 Jun; 9(6):595-8.

4. Berger JT. Ethics of Practicing Medical Procedures on Newly Dead and Nearly Dead Patients. J Gen Intern Med. 2002 October; 17(10): 774-8.

5. Schmidt et al. Ethics Seminars: The Ethical Debate on Practicing Procedures on the Newly Dead. Acad Emerg Med. Sept 2004; 11( 9): 962-6.

6. Brattebo G. Wisborg T. Solheim K et al. Public opinion on different approaches to teaching intubation techniques. BMJ. 1993 Nov 13; 307(6914):1256-7.

7. Manifold CA. Storrow A. Rodgers K. Patient and family attitudes regarding the practice of procedures on the newly deceased. Acad Emerg Med. Feb 1999; 6(2):110-5.

8. The Council on Ethical and Judicial Affairs of the American Medical Association. Performing Procedures on the Newly Deceased. Acad Med. Dec 2002; 77(12 Pt 1):1212-6.

9. Abramson N. de Vos R. Fallat ME et al. American Heart Association. International Liaison Committee on Resuscitation. Ethics in emergency cardiac care. Annals of Emergency Medicine. April 2001; 37(4 Suppl):S196-200.

10. Stratton et al. Prospective Study of mannequin-only versus mannequin and human subject endotracheal intubation training of paramedics. Ann Emerg Med. Dec 1991; 20:1314-8.

11. McPherson JB. Instruction of emergency invasive procedures utilizing human cadavers [abstract]. Ann Emerg Med. 1993; 22,5: 908 .

12. Stewart RD et al. Effect of varied training techniques on field endotracheal intubation success rates. Ann Emerg Med.1984; 13: 1032-6.

13. Hauswald M. Tuohy G F. Von der Heydt P. Adequate training for endotracheal intubation. Ann Emerg Med. Sept 1992; 21(9):1168-9.

Marta Karczewska (M.D C.M 2010) is an internal editor at the McGill Journal of Medicine. She completed her Medical Preparatory year at McGill in 2006. She is a graduate of the Health Sciences Program at Collège Jean-de-Brébeuf. 